\title{
Distributed Cooperative Control System for Smart Microgrids
}

\author{
R. Jalilzadeh Hamidi ${ }^{\text {a }}$, H. Livani ${ }^{\text {a }}$, S. H. Hosseinian ${ }^{\text {b }}$, G. B. Gharehpetian ${ }^{\text {b }}$ \\ ${ }^{a}$ EBME Department, University of Nevada, Reno, 1664 North Virginia Street, Reno, NV. 89503, USA. \\ $\mathrm{b}$ Electrical Engineering Department, Amirkabir University of Technology (Tehran Polytechnic), 424 Hafez Ave., \\ Tehran, Iran.
}

Abstract—This paper presents a decentralized control method for Electronically Interfaced Distributed Generations (EI-DGs) that controls their output frequencies, power generations, and voltages during grid-connected, islanding, and synchronizing modes. The proposed control system utilizes droop control to quickly balance generation and demand after sudden disturbances. It utilizes distributed cooperative control to stabilize the system frequency and voltage, and also to distribute the generation among DGs. Furthermore, the proposed control system adjusts the frequency and voltage to reconnect the microgrid to the main grid by utilizing only local measurements from the neighboring DGs. The proposed control system is verified on a modified IEEE Standard 399-1997 test system using MATLAB/SIMULINK and the advantages and disadvantages of the proposed method are discussed according to the results.

Index Terms-Distributed cooperative control; Frequency stability; Power sharing; Voltage stability.

\section{Introduction}

Microgrids (MGs) and Distributed Generations (DGs) have been adopted to provide energy resiliency and to enhance environmental benefits. MGs must be able to supply the loads during 
both grid-connected and islanding modes [1], [2]. The main grid controls the frequency and voltage of an MG in grid-connected mode. However, in islanding mode, a control system is needed for frequency and voltage control, and also for sharing the total generation among DGs [3]-[8].

Electronically Interfaced DGs (EI-DGs), such as micro-turbines and Photovoltaic (PV) panels, are connected to AC power grids via power electronic inverters, mainly for adjusting their output frequency [7]. Voltage Source Inverters (VSIs) are widely used for connecting EI-DGs to the grid [5], [8], [9]. Each inverter is equipped with a control system, which pursues the grid control strategy [10]-[12]. The control strategies presented in the literature are broadly divided into two main categories based on their communication requirements:

- Control systems without communications

- Communication-based control systems

A large number of DGs and also fast responses of VSIs may disturb the control systems without communications [7], [10], [13]. Communication-based control systems utilize communications to adopt the grid control strategy [14]-[16]. This will be viable because of proliferation of communications in Smart Microgrids (SMGs) [17]. The communication-based control systems are divided into centralized or decentralized systems.

Centralized control systems require complex communication networks [15], [16], [18]. Despite improvements in communications, the cost and reliability of communication networks are still a great source of concern [5], [10]. Moreover, centralized controllers are neither self-organizing nor highly scalable [19]-[23]. Compared to the centralized control systems, decentralized control systems are more reliable, less expensive, and they also provide scalability and self-organizing requirements for SMGs [5], [10], [19], [20], [24]. 
Applications of distributed cooperative control in power systems as a decentralized control system have been proposed in the literature. In [5], the secondary controller based on distributed cooperative control is proposed to regulate the voltage in islanding mode. In [6], a distributed adaptive control system with time varying communication topology is introduced. This system regulates the voltage of SMGs with variable load in islanding mode. Bidram et al propose a secondary controller for returning the upset voltage and frequency of the SMGs during islanding mode by utilizing cooperative control [8]. Xin et al propose Fair Utilization method to share power among DGs during grid-connected mode [10]. Maknouninejad et al utilize cooperative control to optimally dispatch the power generation among a large number of DGs where conventional optimal power flow is not practical nor economical; they also address voltage regulation [11]. In [12], cooperative-based optimal dispatch of reactive generation among DGs in grid-connected mode is proposed. Vaccaror et al present a decentralized non-hierarchal voltage regulation method to optimally improve the voltage profile and to remove the probable local voltage anomalies in grid-connected mode [19]. Maknouninejad et all propose an optimal design of communication links for power sharing with different communication frequencies [20]. A cooperative-based control system for minimizing voltage deviations and preventing voltage violations during tapchanger transformer adjustments is presented in [21]; it also prevents DGs from reducing power generation as much as possible. In [22], cooperative control is utilized for voltage control and power sharing during grid-connected mode such that the reactive flow is reduced. In [23], cooperative control is employed to regulate both frequency and voltage of SMGs in islanding mode. It also shares power among DGs such that the output of the energy storage system becomes zero. 
In this paper, we present a decentralized control system, including the secondary and tertiary controllers both based on distributed cooperative control. It extends several previous works on cooperative control. The proposed control system is able to control the frequency and voltage of SMGs and share demand among the DGs during grid-connected, islanding, and synchronizing operating modes (synchronizing mode is the transition from islanding to grid-connected mode [7]). The main features of the proposed control system are listed as:

- It is self-organizing and largely scalable

- Only sparse communication infrastructure is required

- It prevents DC bus voltages of VSIs from dropping

The contributions of this paper are: 1) An integrated control system is proposed that supports all three SMG operating modes. 2) It is able to match the voltage magnitudes and voltage angles of the PCC and the main grid during synchronizing mode for smooth reconnection to the main grid.

Our proposed control system uses the common hierarchal control structure in power systems, that is, the primary, secondary, and tertiary control levels. In this paper, each VSI is assumed to be equipped with a local controller based on the droop characteristics. In the event of disturbances in power systems, the frequency and voltage may deviate. The cooperative controller updates the set points of the droop characteristics to return the upset frequency and voltage, and to share demand among DGs. The performance of the proposed control system is verified by the simulation results, and its pros and cons are discussed according to the results.

This paper is organized as follows: Section 2 presents VSI model, communication network, and the control system objectives. In section 3, the proposed control system structure is described and 
designed. In section 4, the proposed control system is verified and the results are discussed. In section 5, the conclusion is presented. Appendix A presents VSI model in detail. Numerical values of VSI parameters and integrator gains are stated in Appendix B. In Appendix C, Laplacian matrices, the input matrices for the test case cooperative controller, and the controller stability are provided.

\section{Problem Formulation}

\section{1. Mathematical Models}

The Differential Algebraic Equations (DAEs) describing the VSIs with decoupled $d-q$ control method via Phase Locked Loop (PLL) are presented in Appendix A. The compact form of the large-signal dynamic model of VSIs is [5]

$$
\left\{\begin{array}{c}
\dot{x}_{i}=f_{i}\left(\boldsymbol{x}_{i}\right)+g_{i}\left(\boldsymbol{x}_{i}\right) \boldsymbol{u}_{i} \\
\boldsymbol{y}_{i}=h_{i}\left(\boldsymbol{x}_{i}\right)
\end{array}, \forall i\right.
$$

where $f_{i}, g_{i}$, and $h_{i}$ are obtained from the DAEs in Appendix A. $\boldsymbol{x}_{i}$ is the vector of internal state variables of the $i^{t h}$ VSI. $\boldsymbol{y}_{i}=\left[\omega_{i}, V_{i}\right]^{T}$ is the output vector of the $i^{t h}$ VSI. $\boldsymbol{u}_{i}=\left[\omega_{d_{i}}^{*}, V_{d_{i}}^{*}, V_{q_{i}}^{*}\right]^{T}$ is the input vector to the $i^{t h}$ VSI, which is calculated by cooperative control in the proposed method. The general form of cooperative control is [25], [26]

$$
\dot{u}=-L u+B v
$$

where $\boldsymbol{u}=\left[\boldsymbol{u}_{\boldsymbol{i}}\right]^{T}, \boldsymbol{u}_{\boldsymbol{i}}$ is the input to VSIs, $\boldsymbol{B}$ is the input matrix, $\boldsymbol{v}$ is the cooperative controller input vector, $\boldsymbol{L}=\left[l_{i j}\right]$ is the graph Laplacian of communication network, defined as follows

$$
l_{i j}=\left\{\begin{array}{c}
-1, j \in N_{i} \\
\left|N_{i}\right|, j=i
\end{array}\right.
$$


where $N_{i}$ is the set of the agents that directly send their information to the $i^{\text {th }}$ agent (the neighbors of the $i^{\text {th }}$ agent). $\left|N_{i}\right|$ denotes the size of $N_{i}$ (in-degree of the $i^{t h}$ agent) [25], [26].

The SMG supplies the loads with respect to the following constraints

$$
\left\{\begin{array}{c}
\sum P_{g_{i}}+P_{t r}=\sum P_{D}+P_{\text {loss }} \\
\sum Q_{g_{i}}+Q_{t r}=\sum Q_{D}+Q_{\text {loss }} \\
\omega_{\min } \leq \omega_{i} \leq \omega_{\max } \\
V_{\min } \leq V_{i} \leq V_{\max }
\end{array}, \forall i\right.
$$

where $P_{g_{i}}$ and $Q_{g_{i}}[\mathrm{pu}]$ are the active and reactive output powers of the $i^{\text {th }}$ VSI . $P_{D}[\mathrm{pu}]$ and $Q_{D}$ [pu] are demands. $P_{t r}$ and $Q_{t r}[\mathrm{pu}]$ are the active and reactive powers passing through the transformer, as shown in Fig. 1. $P_{\text {loss }}$ and $Q_{\text {loss }}[\mathrm{pu}]$ are the losses in the grid. $V_{i}[\mathrm{pu}]$ is the $i^{\text {th }}$ VSI voltage which is limited to $V_{\min }$ and $V_{\max }[\mathrm{pu}] . \omega_{i}[\mathrm{rad} / \mathrm{s}]$ is the $i^{\text {th }}$ inverter output frequency which is limited to $\omega_{\min }$ and $\omega_{\max }[\mathrm{pu}]$.

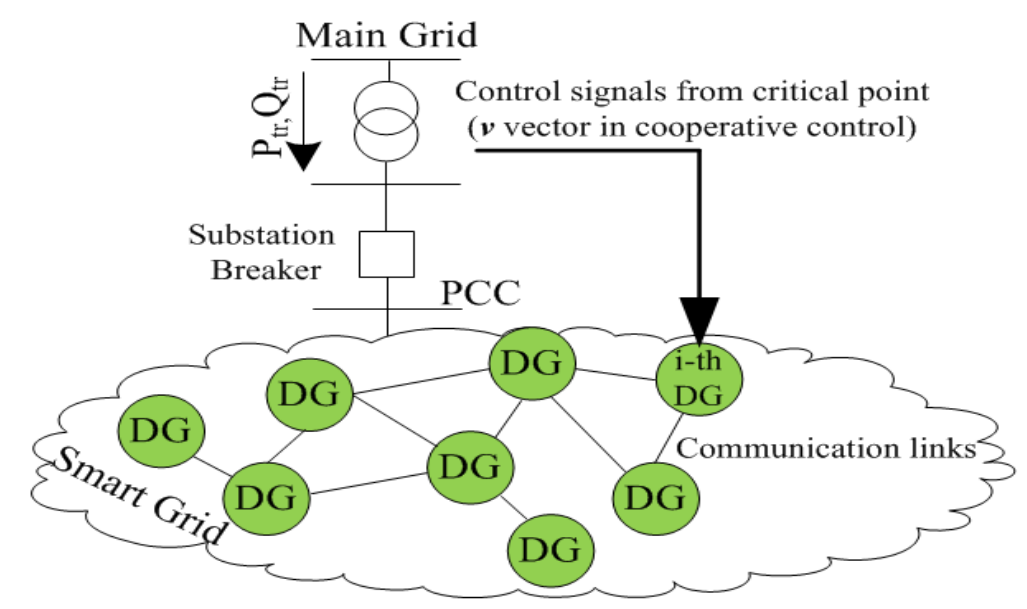

Fig. 1. A smart microgrid with its communication links.

\subsection{Control System Objectives}

The control system objectives are stated in Eqs. (5)-(9), as follows: 
- Power Sharing: The adopted power sharing method in this work is the Fair Utilization method in which all DGs generate power at the same ratio [10]-[12]. The Fair Utilization method is mathematically stated as

$$
\begin{aligned}
& \frac{P_{g_{1}}}{P_{g_{1}}^{\max }}=\frac{P_{g 2}}{P_{g_{2}}^{\max }}=\cdots=\frac{P_{g_{i}}}{P_{g_{i}}^{\max }}, \forall i \\
& \frac{Q_{g_{1}}}{Q_{g_{1}}^{\max }}=\frac{Q_{g_{2}}}{Q_{g_{2}}^{\max }}=\cdots=\frac{Q_{g_{i}}}{Q_{g_{i}}^{\max }}, \forall i
\end{aligned}
$$

where $P_{g_{i}}$ and $Q_{g_{i}}$ [pu] are the $i^{t h}$ VSI generation. $P_{g_{i}}^{\max }$ and $Q_{g_{i}}^{\max }$ are the maximum generation capacity of the $i^{\text {th }}$ VSI at any given time in [pu].

According to market or technical conditions, the SMG operator wants to exchange different amount of power with the main grid through the distribution transformer. However, as there is no data fusion or control center and the fact that most of the renewable energy-based generation units are non-dispatchable, the desired power to be exchanged may not be realized. The proposed control system brings the exchanged power as close as possible to the desired (reference) values as,

$$
P_{t r} \rightarrow P_{t r}^{r e f}, Q_{t r} \rightarrow Q_{t r}^{r e f}
$$

where $P_{t r}$ and $Q_{t r}[\mathrm{pu}]$ are the measured exchanged powers with the main grid, $P_{t r}^{r e f}$ and $Q_{t r}^{r e f}[\mathrm{pu}]$ are the desired values for the exchanged powers. The selection of the reference values is described in Section 3.1. The sign ' $\rightarrow$ ' indicates that the left side approaches the right side.

According to Appendix A, the maximum power generation capability of each VSI is limited to its input from DC bus. The Fair Utilization power sharing method prevents the VSIs to violate this limitation.

- Voltage Objective: The voltages of VSIs are controlled to become close to one another which results in a decrease in reactive power flow in the SMG. Referring to Fig. 1, reconnection to the 
main grid necessitates that both terminal voltages of the substation breaker are almost the same. The mathematical representation of these objectives are given as

$$
V_{i} \rightarrow V_{j}: V_{P C C} \rightarrow V_{\text {MainGrid }}, \forall i \neq j
$$

where $V_{i}$ and $V_{j}[\mathrm{pu}]$ are the output voltage of the $i^{\text {th }}$ and $j^{\text {th }}$ VSIs, $V_{P C C}$ and $V_{\text {MainGrid }}[\mathrm{pu}]$ are the voltages of PCC and the main grid, respectively, and the sign ':' denotes 'such that'.

- Frequency Objective: The frequencies of all VSIs are adjusted at $\omega_{\text {ref }}[\mathrm{rad} / \mathrm{s}]$ to match the frequencies and phase angles of the PCC and the main grid.

$$
\omega_{i} \rightarrow \omega_{\text {ref }}: \theta_{P C C} \rightarrow \theta_{\text {MainGrid }}, \forall i
$$

where $\omega_{i}[\mathrm{rad} / \mathrm{s}]$ is the output frequency of the $i^{\text {th }}$ VSI. $\theta_{P C C}$ and $\theta_{\text {MainGrid }}$ are the phase angles [rad] of the PCC and main grid, respectively.

\section{Proposed Control System Structure and Design}

Similar to the common control systems in power systems, the proposed method has a threelayer hierarchical structure [5], [7], [27]-[29]. The primary controller responds to sudden changes in generation and demand to retain the balance between generation and demand [3]-[7]. Unlike synchronous generators, the output frequencies of VSIs are independent from their power outputs in nature. Therefore, the power outputs of the VSIs are measured, and droop controllers then change the output frequencies proportional to the power outputs [9]. In this paper, the primary control is locally installed on every single VSI, and the frequency and voltage droop characteristics are

$$
\omega_{i}^{*}=\omega_{0_{i}}-\kappa_{p_{i}}\left(P_{g_{i}}-P_{0_{i}}\right)
$$




$$
\begin{aligned}
V_{d_{i}}^{*} & =V_{d 0_{i}}-\kappa_{Q_{i}}\left(Q_{g_{i}}-Q_{0_{i}}\right) \\
V_{q_{i}}^{*} & =0
\end{aligned}
$$

where $\omega_{i}^{*}[\mathrm{pu}]$ and $V_{d_{i}}^{*}[\mathrm{pu}]$ are frequency and voltage commands to the $i^{\text {th }}$ inverter. $V_{q_{i}}^{*}$ is zero as $d$ $q$ rotational frame is attached to the output voltage. $P_{0_{i}}, Q_{0_{i}}, \omega_{0_{i}}$, and $V_{d 0_{i}}$ are the dynamic set points in the droop equations. $P_{g_{i}}$ and $Q_{g_{i}}$ are active and reactive generations of the $i^{\text {th }}$ VSI, calculated as

$$
\begin{gathered}
P_{g_{i}}=\frac{\omega_{c_{i}}}{S+\omega_{c_{i}}}\left(V_{d_{i}} i_{d_{i}}+V_{q_{i}} i_{q_{i}}\right) \\
Q_{g_{i}}=\frac{s}{S+\omega_{c_{i}}}\left(V_{q_{i}} i_{q_{i}}-V_{d_{i}} i_{q_{i}}\right)
\end{gathered}
$$

where $V_{d_{i}}, V_{q_{i}}, i_{d_{i}}$, and $i_{q_{i}}$ are the direct and quadratic components of the voltage and current, respectively. $\omega_{c_{i}}[\mathrm{rad} / \mathrm{s}]$ is the cut-off frequency of the low-pass filter [5], [9], and ' $S$ ' denotes Laplace transformation.

System stability is the ability of a system to return to the normal operation after some forms of disturbance [5], [27]-[29]. The secondary controller returns the frequency and voltage to the normal values after disturbances to make the system stable. The secondary controller usually uses communications, and provides global controllability for power systems [16].

The tertiary controller updates $P_{0_{i}}$ and $Q_{0_{i}}$ set points in droop characteristics depending on the system requirements. In power systems, the system operator usually updates these set points according to the status of the generating units, power system conditions, and demand [5], [16], [27].

\subsection{Controller Design}


In this paper, the control system goal is to update the set points in Eqs. (10) and (11) such that the constraints in Eq. (4) are satisfied during all SMG operating modes. In this regard, we assumed that all VSIs are equipped with a local controller that receives frequency, voltage, and power set points from neighboring VSIs as well as local data, as shown in Fig. 2(a). Then, utilizing the received data, the cooperative control updates the set points of the local primary controllers, as shown in Fig. 2(b). In order to design the control system the flowing assumption has been made [5], [9]

$$
\omega_{i} \approx \omega_{i}^{*}, V_{d_{i}} \approx V_{d_{i}}^{*}, V_{q_{i}} \approx V_{q_{i}}^{*}
$$

Applying Eq. (14) to Eqs. (10) and (11) results in

$$
\begin{gathered}
\omega_{i}=\omega_{0_{i}}-\kappa_{p_{i}}\left(P_{g_{i}}-P_{0_{i}}\right) \\
V_{d_{i}}=V_{d 0_{i}}-\kappa_{Q_{i}}\left(Q_{g_{i}}-Q_{0_{i}}\right)
\end{gathered}
$$

where $\omega_{0_{i}}, V_{d 0_{i}}, P_{0_{i}}$, and $Q_{0_{i}}$ are dynamic set points of the primary controllers which are updated by the cooperative controller through an integrator (PI) as follows

$$
\begin{array}{rlrl}
P_{0_{i}} & =\mathrm{K}_{P_{i}} \int \dot{P}_{i} d t, & & \dot{\boldsymbol{P}}=-\boldsymbol{L}_{p} \boldsymbol{P}+\boldsymbol{B}_{P} \boldsymbol{v}_{P} \\
Q_{0_{i}} & =\mathrm{K}_{Q_{i}} \int \dot{Q}_{i} d t, & & \dot{\boldsymbol{Q}}=-\boldsymbol{L}_{Q} \boldsymbol{Q}+\boldsymbol{B}_{Q} \boldsymbol{v}_{Q} \\
\omega_{0_{i}}=\mathrm{K}_{\omega_{i}} \int \dot{\omega}_{i} d t, & & \dot{\boldsymbol{\omega}}=-\boldsymbol{L}_{\omega} \boldsymbol{\omega}+\boldsymbol{B}_{\omega} \boldsymbol{v}_{\omega} \\
V_{d 0_{i}}=\mathrm{K}_{V_{i}} \int \dot{V}_{d_{i}} d t, & \dot{\boldsymbol{V}}_{d}=-\boldsymbol{L}_{V} \boldsymbol{V}_{d}+\boldsymbol{B}_{d} \boldsymbol{v}_{d}
\end{array}
$$

where $\mathrm{K}_{P_{i}}, \mathrm{~K}_{Q_{i}}, \mathrm{~K}_{\omega_{i}}$, and $\mathrm{K}_{V_{i}}$ are the gain factors for the $i^{t h}$ integrator (PI), $\boldsymbol{L}_{p}, \boldsymbol{L}_{Q}, \boldsymbol{L}_{\omega}$, and $\boldsymbol{L}_{V}$ are graph Laplacian matrices based on the communication topology. $\boldsymbol{P}, \boldsymbol{Q}, \boldsymbol{\omega}$, and $\boldsymbol{V}_{d}$ are the cooperative controller state vectors, defined as follows 


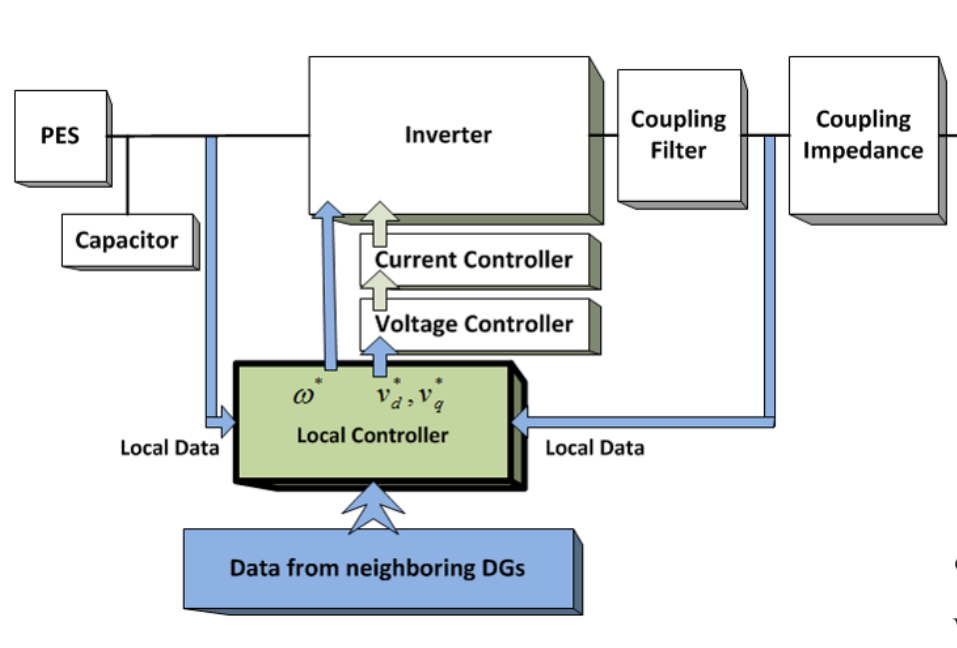

(a)

$$
\begin{aligned}
& \boldsymbol{P}=\left[\frac{P_{0_{1}}}{P_{0_{1}}^{\max }}, \frac{P_{0_{2}}}{P_{0_{2}}^{\max }}, \ldots, \frac{P_{0_{n}}}{P_{0_{n}}^{\max }}\right]^{T} \\
& \boldsymbol{Q}=\left[\frac{Q_{0_{1}}}{Q_{0_{1}}^{\text {max }}}, \frac{Q_{0_{2}}}{Q_{0_{2}}^{\text {max }}}, \ldots, \frac{Q_{0_{n}}}{Q_{0_{n}}^{\text {max }}}\right]^{T} \\
& \boldsymbol{\omega}=\left[\omega_{0_{1}}, \omega_{0_{2}}, \ldots, \omega_{0_{n}}\right]^{T} \\
& \boldsymbol{V}_{\boldsymbol{d}}=\left[V_{d 0_{1}}, V_{d 0_{2}}, \ldots, V_{d 0_{n}}\right]^{T}
\end{aligned}
$$

and $\boldsymbol{B}_{P}, \boldsymbol{B}_{Q}, \boldsymbol{B}_{\omega}$, and $\boldsymbol{B}_{d}$ are cooperative controller input vectors, where $\boldsymbol{B}=\left[b_{i}\right]$, and $b_{i}=1$, if the $i^{\text {th }}$ VSI receives control signals from the critical point, else $b_{i}=0 . \boldsymbol{v}$ 's are input vectors to the cooperative controller from the critical point. During grid-connected mode, the input vectors are as follows

$v_{\boldsymbol{P}}=\left[v_{p_{i}}\right]^{T}, v_{p_{i}}=P_{t r}^{r e f}-P_{t r}$, if the $i^{\text {th }}$ VSI receives control signals from the critical point, else $v_{p_{i}}=0$.

$\boldsymbol{v}_{Q}=\left[v_{Q_{i}}\right]^{T}, v_{Q_{\mathrm{i}}}=Q_{t r}^{r e f}-Q_{t r}$, if the $i^{\text {th }}$ VSI receives control signals from the critical point, else $v_{Q_{i}}=0$. 
$\boldsymbol{v}_{\omega}=\left[v_{\omega_{i}}\right]^{T}, v_{\omega_{i}}=\frac{\partial\left(\theta_{\text {MainGrid }}-\theta_{P C C}\right)}{\partial t}$, if the $i^{t h}$ VSI receives control signals from the critical point, else $v_{\omega_{i}}=0$.

$v_{d}=\left[v_{d_{i}}\right]^{T}, v_{d_{i}}=V_{d_{\text {MainGrid }}}-V_{d_{P C C}}$, if the $i^{t h}$ VSI receives control signals from the critical point, else $v_{\mathrm{d}_{i}}=0$.

where $P_{t r}$ and $Q_{t r}[\mathrm{pu}]$ are active and reactive powers transferring via the transformer, as shown in Fig. $1, P_{t r}^{r e f}$ and $Q_{t r}^{r e f}$ are the desired values for the powers passing via the transformer. The total generation in the SMG is adjusted such that $P_{t r} \rightarrow P_{t r}^{r e f} \cdot V_{d_{M a i n G i d}}$ and $V_{d_{P C C}}$ are the d-axis voltages of the main grid and PCC. In Eq. (18c), $\partial\left(\theta_{\text {MainGrid }}-\theta_{P C C}\right) / \partial t$ is numerically calculated by successive synchronized measurement of PCC and main grid voltage angles as

$$
v_{\omega_{i}}=\frac{\partial\left(\theta_{\text {MainGrid }}-\theta_{P C C}\right)}{\partial t}=\frac{\left(\theta_{\text {MainGrid }}-\theta_{P C C}\right)^{(k)}-\left(\theta_{\text {MainGrid }}-\theta_{P C C}\right)^{(k-1)}}{\Delta t}
$$

where $(.)^{k}$ and (. $)^{k-1}$ indicate successive measurements with a time interval of $\Delta t$. Applying (19) into the integrator in Eq. (16c) yields $\left(\omega_{\text {MainGrid }}-\omega_{P C C}\right)$ which matches the frequencies of the PCC and the main grid.

Since islanding usually occurs after a contingency in the main grid, it is highly probable that the main grid is not in normal state during islanding mode. Therefore, during islanding, the control signals from critical point should be change as follows: in Eqs. (18a) and (18b), $P_{t r}^{r e f}=Q_{t r}^{r e f}=$ 0 because there is no power flow through the transformer. In Eq. $(18 \mathrm{c}), v_{\omega_{i}}=\frac{\partial\left(1[\mathrm{pu}]-\omega_{P C C}\right)}{\partial t}$ if the $i^{t h}$ VSI receives control signals from the critical point, else $v_{\omega_{i}}=0$. In Eq. (18d), $V_{d_{\text {MainGrid }}}=1$ [pu] must be selected. 
During synchronizing mode, the control signals from critical point are as follows: in Eqs. (18a) and $(18 \mathrm{~b}), P_{t r}^{r e f}=Q_{t r}^{r e f}=0$. Smooth reconnection to the main grid requires that the voltage magnitude, voltage angle, and frequency of the main and smart grids are the same. In this regard, the signals from the critical point for voltage control is the same as Eqs. (18d). However, in order to match both the frequencies and voltage angles of the PCC and main grid, the input to the cooperative control in Eq. (18c) is defined as

$$
v_{\omega_{i}}=\frac{\partial\left(\theta_{\text {MainGrid }}-\theta_{P C C}\right)}{\partial t}+\frac{\partial^{2}\left(\theta_{\text {MainGrid }}-\theta_{P C C}\right)}{\partial t^{2}}
$$

where the first-derivative is calculated as shown in Eq. (19), and the second-derivative is calculated as

$$
\frac{\partial^{2}\left(\theta_{\text {MainGrid }}-\theta_{P C C}\right)}{\partial t^{2}}=\frac{\left(\theta_{\text {MainGrid }}-\theta_{P C C}\right)^{(k)}-2\left(\theta_{\text {MainGrid }}-\theta_{P C C}\right)^{(k-1)}+\left(\theta_{\text {MainGrid }}-\theta_{P C C}\right)^{(k-2)}}{\Delta t^{2}}
$$

where $(.)^{k},(.)^{k-1},(.)^{k-2}$ indicate successive measurements with a time interval of $\Delta t$. Applying (20) into the integrator in Eq. (16c) brings the frequency and voltage angle of the PCC close to those of the main grid.

\subsection{Illustrative case study}

Assume the system shown in Fig. 3 is working in steady state with the following assumptions: $P_{g_{1}}^{\max }=2, P_{g_{2}}^{\max }=1, P_{t r}=1, P_{g_{1}}=\frac{2}{3}, P_{g_{2}}=\frac{1}{3}$, and $\sum P_{D}=2[\mathrm{pu}]$. The system operator decides to set $P_{t r}^{r e f}=0.5[\mathrm{pu}]$ to receive less power from the main grid and to generate more power in the SMG. Assume $\mathrm{K}_{P_{i}}=0.25$; time step, $\Delta t=1[\mathrm{~s}]$.

$\dot{\boldsymbol{P}}=-\boldsymbol{L}_{\boldsymbol{p}} \boldsymbol{P}+\boldsymbol{B}_{P} \boldsymbol{v}_{P}$ 


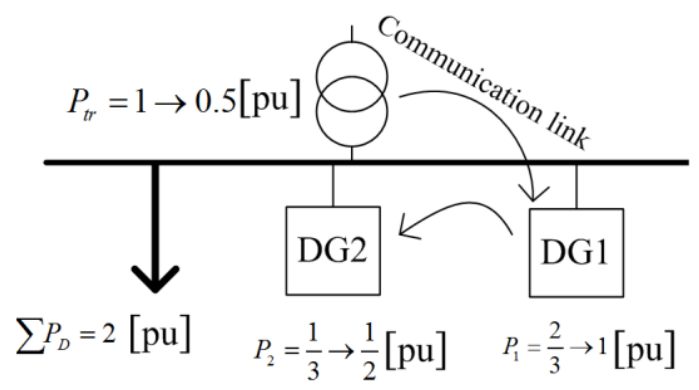

Fig. 3. Schematic of the illustrative case study.

$\dot{\boldsymbol{P}}=-\boldsymbol{L}_{P}\left[\begin{array}{c}\frac{P_{0_{1}}}{P_{0_{1}}^{\max }} \\ \frac{P_{0_{2}}}{P_{0_{2}}^{\max }}\end{array}\right]+\boldsymbol{B}_{P}\left[\begin{array}{c}P_{t r}-P_{t r}^{r e f} \\ 0\end{array}\right] \rightarrow \dot{\boldsymbol{P}}^{(0)}=-\left[\begin{array}{cc}0 & 0 \\ -1 & 1\end{array}\right]\left[\begin{array}{c}\frac{2 / 3}{2} \\ \frac{1 / 3}{1}\end{array}\right]+\left[\begin{array}{ll}1 & 0\end{array}\right]\left[\begin{array}{c}0.5 \\ 0\end{array}\right] \rightarrow \dot{\boldsymbol{P}}^{(0)}=\left[\begin{array}{c}0.5 \\ 0\end{array}\right]$

in the first time step, $\boldsymbol{P}^{(1)}=\boldsymbol{P}^{(0)}+\mathrm{K}_{P_{i}} \dot{\boldsymbol{P}}^{(0)}=[0.4583,0.4583]^{T}$, in the second step, $\boldsymbol{P}^{(2)}=$ $[0.4896,0.4896]^{T}$, and finally, $P \rightarrow[0.5,0.5]$. Then, $\frac{P_{0_{1}}}{2}=0.5, \frac{P_{0_{2}}}{1}=0.5$, implies $P_{0_{1}}=1, P_{0_{2}}=$ 0.5 , and $P_{t r}=0.5[\mathrm{pu}]$, which satisfies $P_{0_{1}}+P_{0_{2}}+P_{t r}=\sum P_{D}$, (i.e., $1+0.5+0.5=2$ ).

\section{Case Study and Simulation Results}

The effectiveness of the proposed control system is verified on a modified IEEE standard 3991997 [30]. The network is simulated using MATLAB/SIMULINK. The details of the network are given in Fig. 4 and Table 1. Data exchange rate (so-called communication frequency, [11], [20], [22]) is 5 [Hz], and communication links are assumed to be ideal [5], [10]. In this case study, it is assumed that the SMG is working in grid-connected mode and already reached its steady-state in normal condition. The SMG is disconnected from the main grid following a contingency (i.e. a fault in the main grid) at $t=1$ [s]. Consequently, the SMG starts working in islanding mode, and 30 seconds later, at $t=31$ [s], the system starts operating in synchronizing mode to reconnect to the main grid. The main grid condition before and after the contingency are given in Table 2 . 
Table 1

Specifications of the loads and DGs in the study system.

\begin{tabular}{|c|c|c|c|c|}
\hline \multirow{4}{*}{ DGs } & \multicolumn{2}{|c|}{ DG1, DG2, \& DG3 } & \multicolumn{2}{|l|}{ DG4 \& DG5 } \\
\hline & Rating & 1.2 [MVA] & Rating & 0.5 [MVA] \\
\hline & $\kappa_{p}$ & 0.003 & $\kappa_{p}$ & 0.072 \\
\hline & $\kappa_{Q}$ & 0.005 & $\kappa_{Q}$ & 0.012 \\
\hline \multirow{3}{*}{ Loads } & L1 \& L4 & L2 \& L5 & L3 \& L7 & L6 \& L8 \\
\hline & $0.1[\mathrm{MW}]$ & $0.25[\mathrm{MW}]$ & $0.5[\mathrm{MW}]$ & $0.2[\mathrm{MW}]$ \\
\hline & 0.483 [MVAR] & 0.12 [MVAR] & 0.241 [MVAR] & 0.097 [MVAR] \\
\hline \multirow[b]{2}{*}{ Total } & \multicolumn{2}{|l|}{ Demand } & \multicolumn{2}{|c|}{ Generation capacity } \\
\hline & $\begin{array}{l}2.1[\mathrm{MW}] \\
1.882[\mathrm{MVAR}]\end{array}$ & & \multicolumn{2}{|l|}{$4.6[\mathrm{MVA}]$} \\
\hline
\end{tabular}

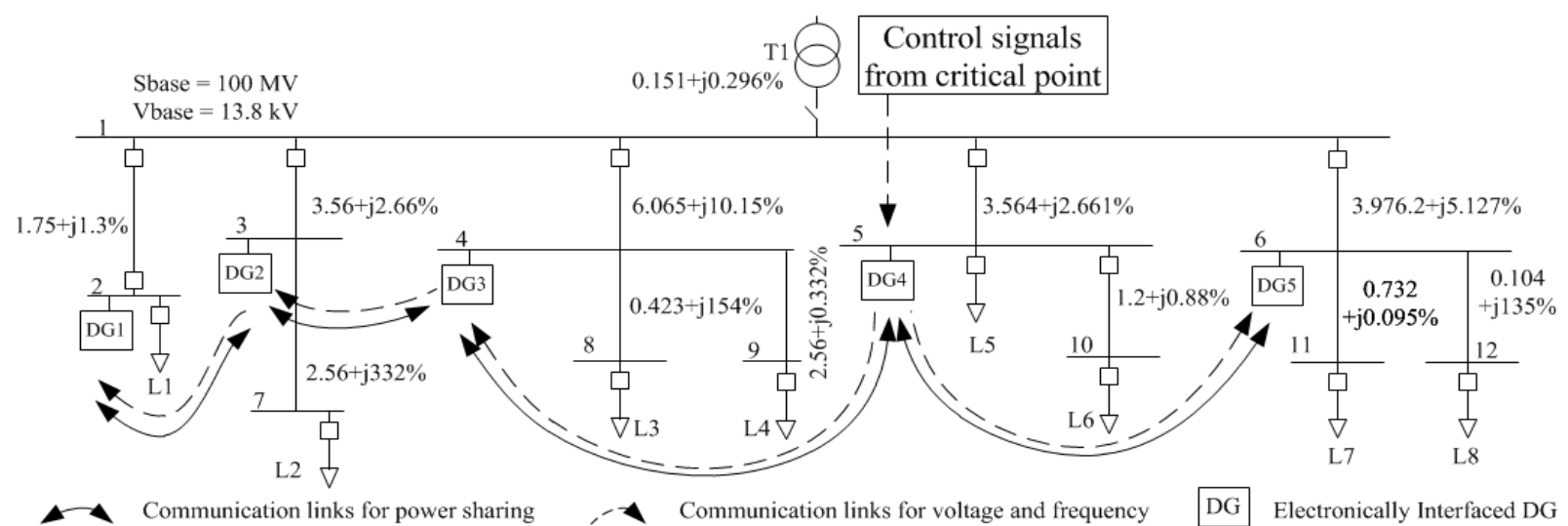

Fig. 4. Single line diagram of the test system with communication links.

\section{1. Results}

Firstly, the stability of the cooperative controller is checked as presented in Appendix C. During grid-connected mode, $0 \leq t<1$ [s], the voltage and frequency of the SMG is controlled by the main grid with the given values in Table 2, ('Before contingency' column) and in the first second of Fig. 5(a), Fig. 6(a)-(c), Fig. 7(a)-(b). The total generation of the DGs is 695 [kW] as given in Table 3 and Fig. 6(c). The generation is 'distributed among all the DGs with the same utilization 
Table 2

Electrical parameters of the main grid before and after the contingency.

\begin{tabular}{l|l|l}
\hline Control Objectives & $\begin{array}{l}\text { Before } \\
\text { contingency }\end{array}$ & $\begin{array}{l}\text { After } \\
\text { contingency }\end{array}$ \\
\hline Voltage & $1[\mathrm{pu}]$ & $0.95[\mathrm{pu}]$ \\
Frequency & $60[\mathrm{~Hz}]$ & $59.9[\mathrm{~Hz}]$ \\
$\mathrm{P}_{\mathrm{tr}}{ }^{*}$ & $1417[\mathrm{~kW}]$ & $0[\mathrm{~kW}]$ \\
Phase difference $(\theta)$ & $0[\mathrm{deg}]$ & $20[\mathrm{deg}]$ \\
\hline
\end{tabular}

* Power passing through the transformer.

Table 3

Power output of the DGs and the distribution transformer.

\begin{tabular}{lll|lll}
\hline \multicolumn{3}{l|}{ Grid-connected mode } & \multicolumn{3}{l}{ Islanding \& synchronizing modes } \\
\hline \multirow{2}{*}{ DG \# } & $\begin{array}{l}\text { Output } \\
{[\mathrm{kW}]}\end{array}$ & Utilization Ratio & DG \# & Output $[\mathrm{kW}]$ & \multirow{2}{*}{ Utilization Ratio } \\
\hline DG1 & 181.3 & $15.1 \%$ & DG1 & 556.67 & $46.39 \%$ \\
DG2 & 181.3 & $15.1 \%$ & DG2 & 556.67 & $46.39 \%$ \\
DG3 & 181.3 & $15.1 \%$ & DG3 & 556.67 & $46.39 \%$ \\
DG4 & 75.54 & $15.1 \%$ & DG4 & 232 & $46.39 \%$ \\
DG5 & 75.54 & $15.1 \%$ & DG5 & 232 & $46.39 \%$ \\
Total $\mathrm{P}_{\text {DGs }}$ & 695 & Not applicable & Total $\mathrm{P}_{\text {DGs }}$ & 2134 & Not applicable \\
$\mathrm{P}_{\text {tr }}$ & 1417 & Not applicable & $\mathrm{P}_{\text {tr }}$ & 0 & Not applicable \\
$\mathrm{P}_{\text {DGs }}+\mathrm{P}_{\mathrm{tr}}$ & 2112 & Not applicable & $\mathrm{P}_{\mathrm{DGs}}+\mathrm{P}_{\mathrm{tr}}$ & 2134 & Not applicable \\
\hline
\end{tabular}

factor of $15.1 \%$, and the rest of the demand $(1417[\mathrm{~kW}])$ is supplied by the main grid as shown in Table 3.

A fault occurs in the main grid at $t=1$ [s]. Consequently, the SMG switches into islanding mode during $1<t<31$ [s]. The power flow through the transformer is zero during islanding mode $\left(P_{t r}=0\right)$ as demonstrated in Table 3 and Fig. 6(c). According to Eqs. (15a) and (15b), the primary controller causes a sharp drop in the system frequency and voltage after the occurrence of the contingency, which are shown in Fig. 5(a) and Fig. 7(a). Subsequently, the cooperative controller, serving as the secondary controller, returns the system frequency and voltage. Fig. 5(a) and Fig. 7(a) show that frequency and voltage increase after the drop. Compared to the gridconnected mode, the VSI voltages are higher in islanding mode mainly due to the change in power 
flow directions and partly due to the higher losses in the SMG. According to Eqs. (5) and (6), DGs generate power at the same utilization ratio. Since the generation capacity of $\mathrm{DG}_{4}$ and $\mathrm{DG}_{5}$ is less than $\mathrm{DG}_{1}$ to $\mathrm{DG}_{3}$, given in Table $1 . \mathrm{DG}_{4}$ and $\mathrm{DG}_{5}$ generate less than the others, as shown in Fig. 6(b) and Table 3. However, all the DGs generate power at the same utilization ratio, Fig. 6(a) and Table 3.
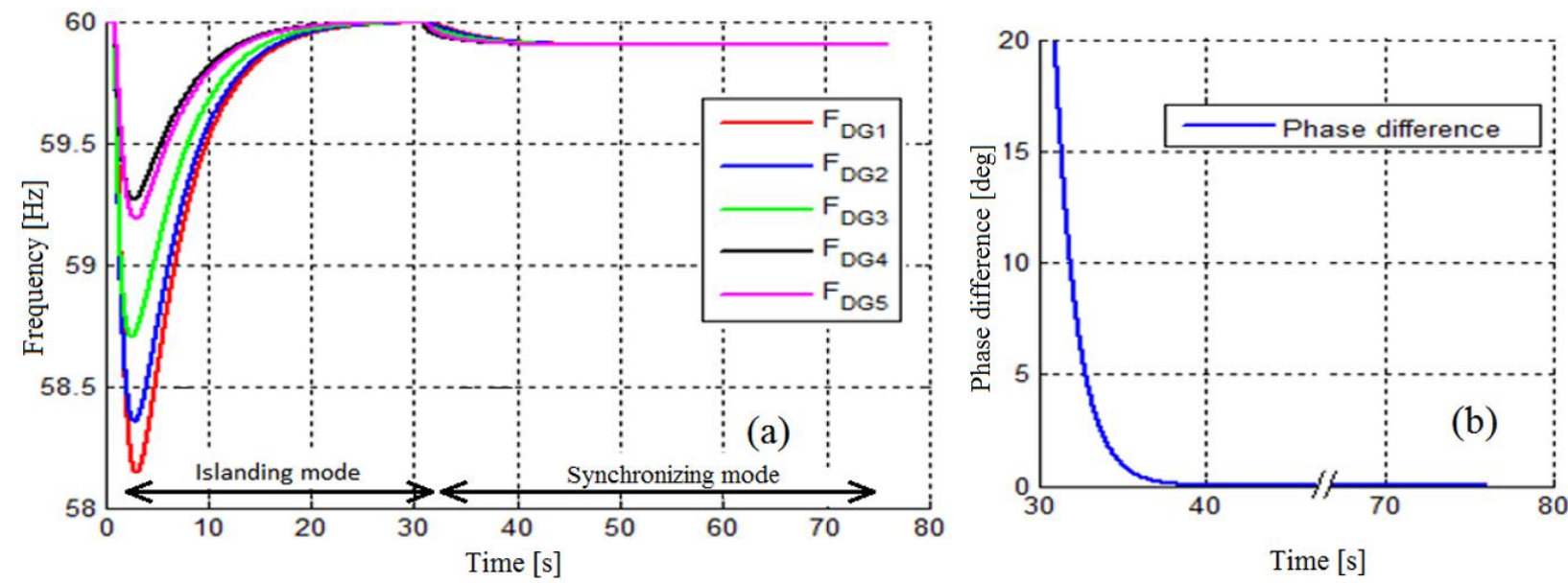

Fig. 5. a) Frequency of VSIs, frequency drops sharply at $\mathrm{t}=1$ [s], after that, the secondary controller returns frequency to $1[\mathrm{pu}]$. b) Phase difference between the PCC and main grid in synchronizing mode $31 \leq t \leq 76[\mathrm{~s}]$.
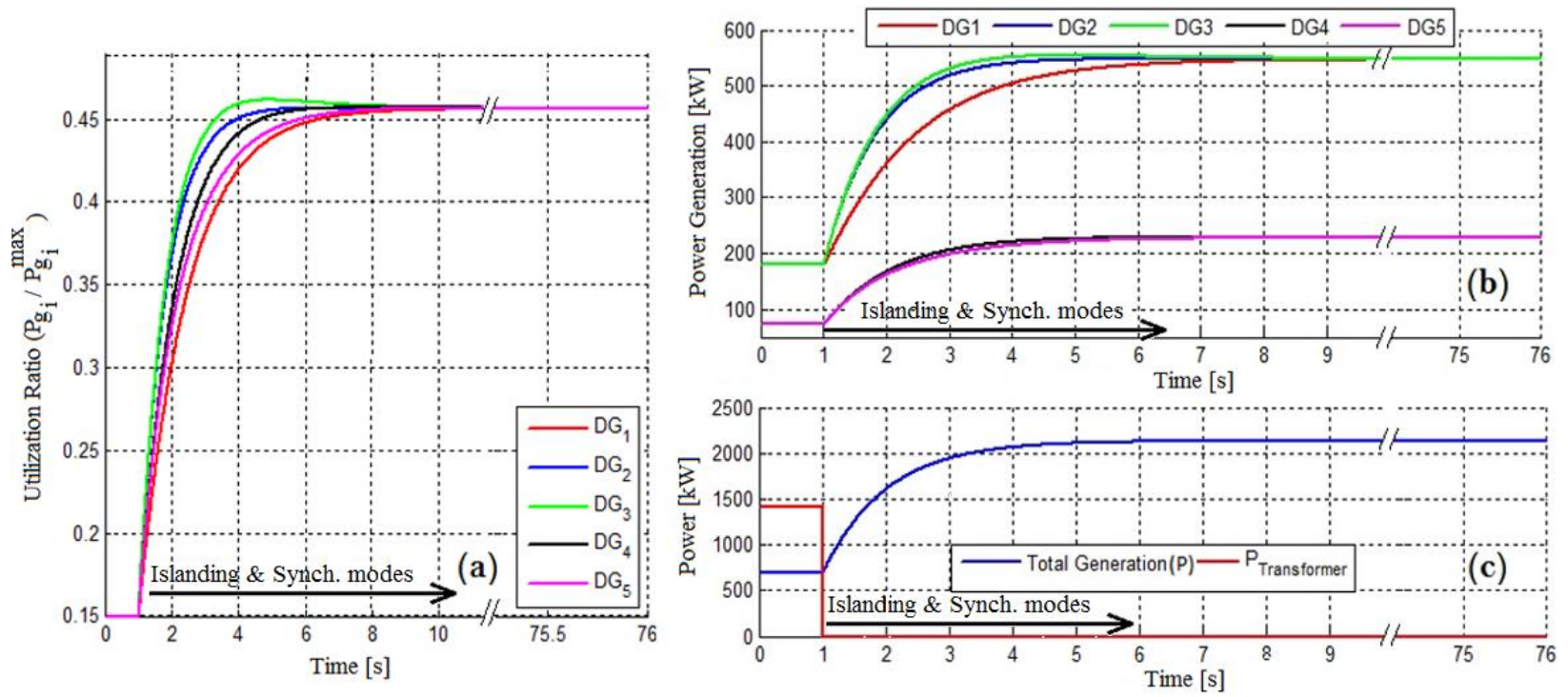

Fig. 6. a) Utilization ratio of DGs, b) Power outputs of DGs, and c) Total generation of DGs and the power passing through distribution transformer. 

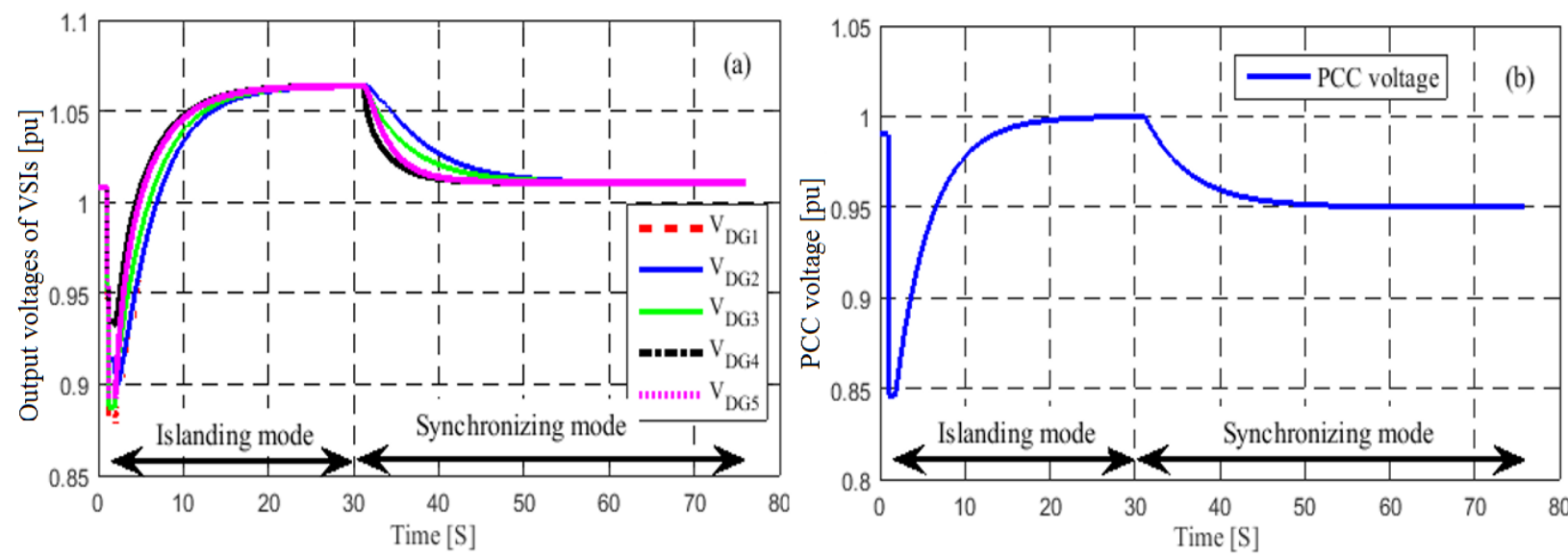

Fig. 7. a) Output voltage of VSIs, a drop at $\mathrm{t}=1$. The secondary controller returns the voltage in $1<\mathrm{t}<30$. In $31<\mathrm{t}$, it changes the voltages of VSIs based on the main grid voltage, $b$ ) the PCC voltage, a drop at $t=1$. The cooperative controller returns the voltage in $1<\mathrm{t}<30$. In $31<\mathrm{t}$, the cooperative controller matches the voltages of PCC and the main grid.

At $t=31$ [s], the SMG switches to synchronizing mode. The change of frequency during synchronizing mode is shown in Fig. 5(a), $t \geq 31$ [s]. All the frequencies of VSIs approach 59.9 $[\mathrm{Hz}]$ instead of the nominal frequency (i.e. $60[\mathrm{~Hz}]$ ) since the main grid frequency is assumed to be $59.9[\mathrm{~Hz}]$ once the contingency is cleared. Fig. 5(b) shows the phase difference between the PCC and the main grid for $t \geq 31$ [s]. As Fig. 5(b) shows, the phase difference is assumed to be $20[\mathrm{deg}]$ at $t=31$ [s], and eventually approaches zero at $t \approx 40$ [s]. As it is observed in Fig. 7(b), the PCC and the main grid voltages are approximately the same for reconnection of the SMG to the main grid. The main grid voltage is 0.95 [pu] (as observed in Table 2). Therefore, the PCC voltage decreases to 0.95 [pu]. However, as it is observed in Fig. 7(a), the voltages of VSIs are greater than $0.95[\mathrm{pu}]$ because of the voltage drops along the feeders. The power generation in synchronizing mode is the same as that in islanding mode (there is no power exchange between the SMG and the main grid during synchronizing mode). Therefore, the utilization ratios and output powers are the same as in islanding mode, as shown in Table 3 and Fig. 6(a)-(c). 


\subsection{Discussion and Comparison}

As it can be observed from the last row in Table 3, our proposed method does not optimally dispatch power among DGs. The total power injection into the SMG is 2112 [kW] and 2134 [kW] during grid-connected and islanding modes, respectively, while the demand is constant 2.1 [MW]. Therefore, power loss increases by $22[\mathrm{~kW}]$ in islanding mode because of the longer distances between the DGs and the loads in islanding mode compared to that in grid-connected mode. Distributed controllers are often compared with central controllers in terms of reliability. Fig. 8 shows the block diagram of a central controller, where $\mathbf{1}=[1,1, \ldots, 1]_{1 \times n}^{T}, n$ is the number of

DGs. $\boldsymbol{K}_{\omega}=\left[\mathrm{K}_{\omega_{1}}, \mathrm{~K}_{\omega_{2}}, \ldots, \mathrm{K}_{\omega_{n}}\right]_{1 \times n}^{T}, K_{\omega_{i}}$ 's are the same as corresponding values of integrators described in (16c) and their values are given in Appendix B. $\omega_{o}^{*}$ is the output vector of the central controller. Communication frequencies of the central and cooperative control methods are the same. Bold lines in Fig. 8 show signal buses, and narrow lines show signals.

The frequency of the $\mathrm{VSI}_{1}$ is considered after the contingency occurrence, Fig. 9. As it is observed, a central controller returns the system frequency to the nominal value faster than the cooperative controller. However, in case of central controller failure (due to adverse weather or cyber-attacks), the SMG becomes unstable. In our cooperatively controlled SMG, if the communication links of VSI 1 are disconnected, there is no failure in the rest of the VSIs. VSI 1 is still equipped with the primary controller and eventually becomes synchronous to the SMG. 


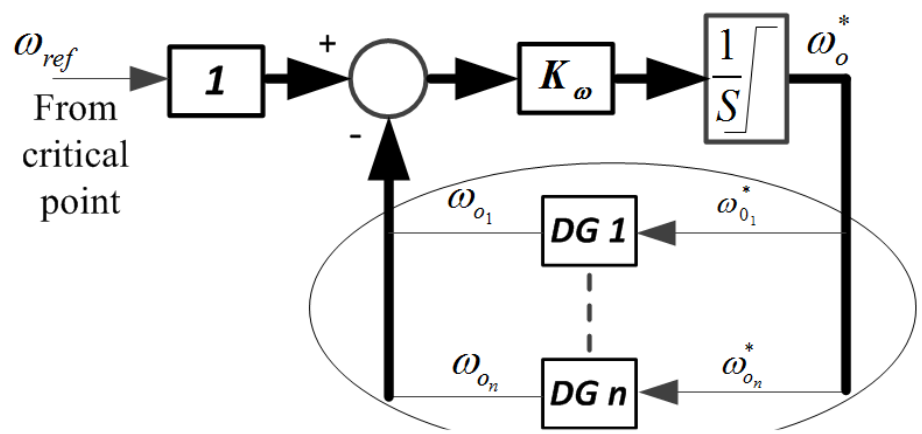

Communication Network

Fig. 8. Block diagram of the central controller compared with the proposed method.

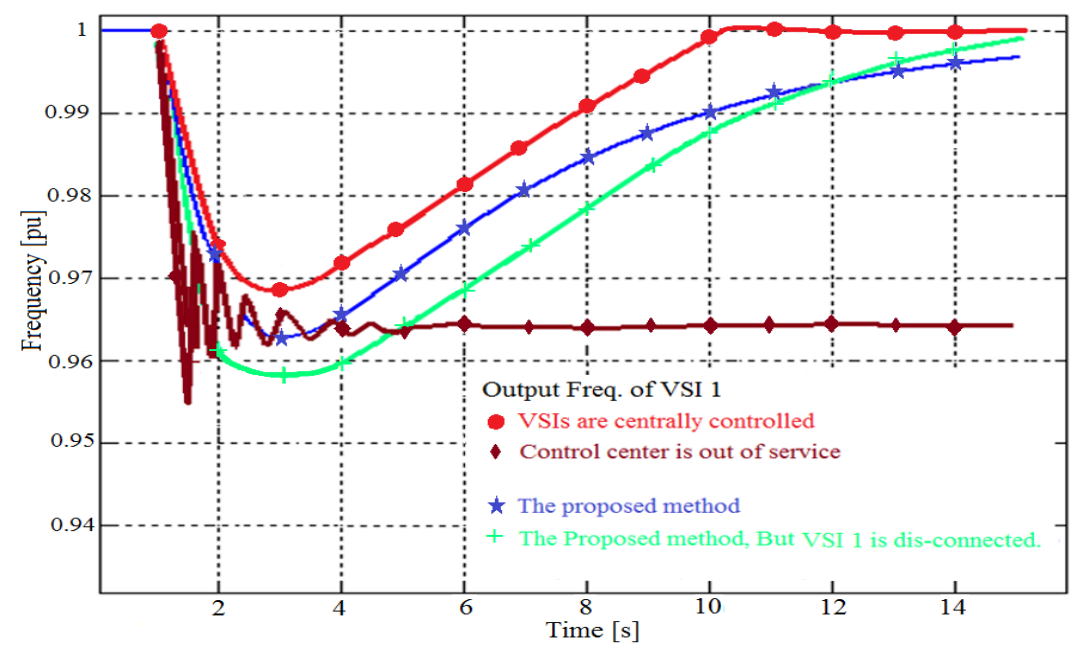

Fig. 9. Comparison of $\mathrm{VSI}_{1}$ frequency under different situations.

Referring to Fig. 10, the proposed method in this paper has satisfactory performance compared to the implemented method in [5]. The comparison is performed under the conditions stated in [5]. The general trends of the output voltages are similar. The proposed control system has lower voltage drops compared to [5], because the proposed system updates the set points for voltage and reactive power at the same time. However, the proposed control system has higher settling time compared to the method stated in [5]. 

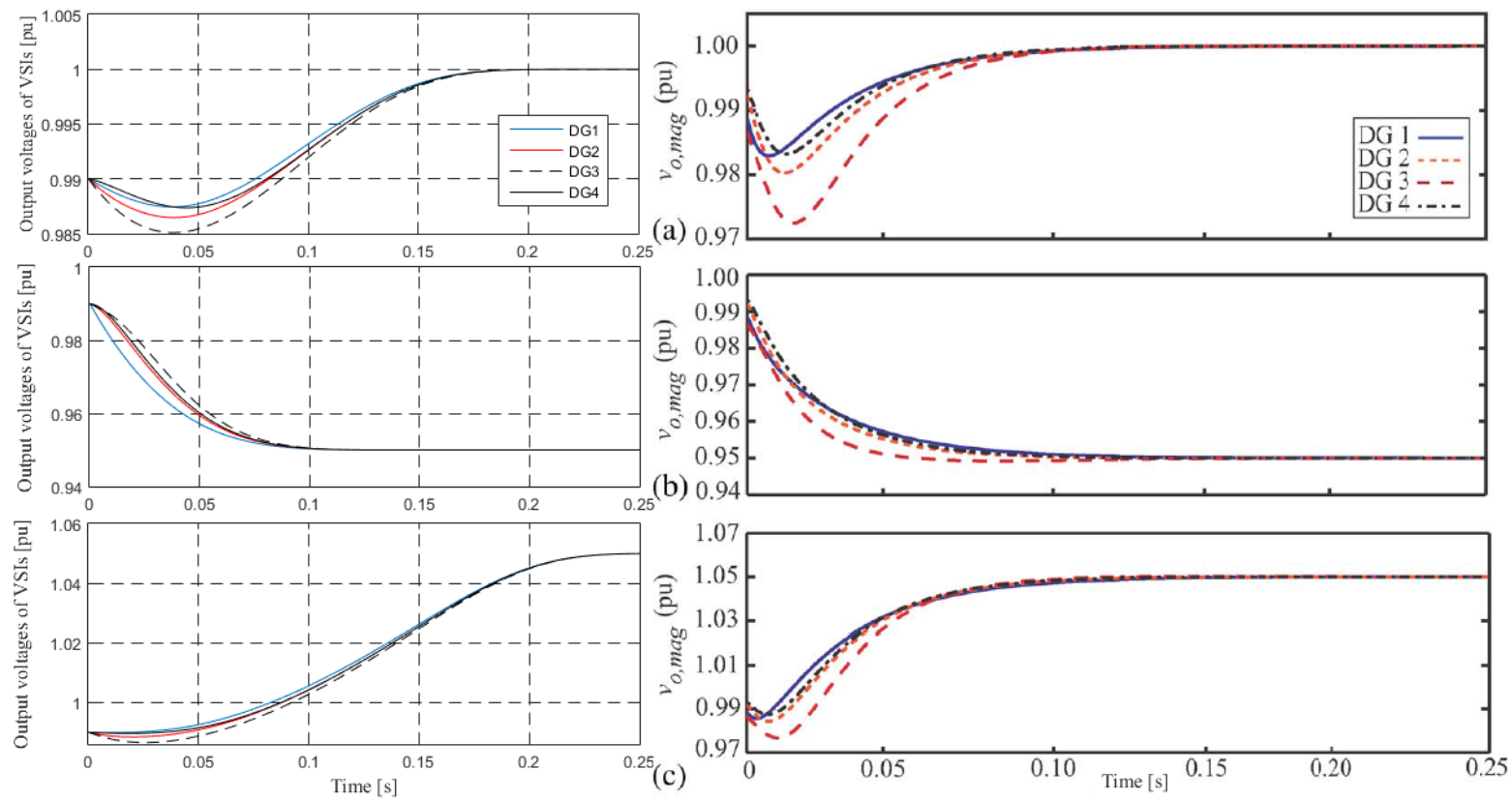

Fig. 10. Comparison of the proposed method with Case A of [5]. The three figures on the right side are from [5].

The capabilities of the proposed method and other cooprative-based control systems in the literature are compared and provided in Table 4.

Table 4

Comparison of the capabilities of different cooperative-based control systems

\begin{tabular}{|c|c|c|c|c|c|c|c|}
\hline \multirow[b]{2}{*}{ Ref. } & \multicolumn{3}{|c|}{ Controlled parameters } & \multicolumn{3}{|c|}{ Supported operating modes } & \multirow{2}{*}{$\begin{array}{c}\text { Need for } \\
\text { Energy } \\
\text { Storage }\end{array}$} \\
\hline & Vol. & Freq. & Generation & $\begin{array}{c}\text { Grid- } \\
\text { connected }\end{array}$ & Islanding & Synchronizing & \\
\hline$[5]$ & $\checkmark$ & & & & $\checkmark$ & & \\
\hline$[6]^{1}$ & $\checkmark$ & & & & $\checkmark$ & & \\
\hline [8] & $\checkmark$ & $\checkmark$ & & & $\checkmark$ & & \\
\hline [10] & & & $\checkmark$ & $\checkmark$ & & & \\
\hline [11] & $\checkmark$ & & & $\checkmark$ & & & \\
\hline [12] & $\checkmark$ & & Opt. $^{2} \mathrm{Q}$ & $\checkmark$ & & & \\
\hline [19] & Opt. & & & $\checkmark$ & & & \\
\hline [20] & $\checkmark$ & & & $\checkmark$ & & & \\
\hline [21] & Opt. ${ }^{3}$ & & $\checkmark$ & $\checkmark$ & & & \\
\hline [22] & $\checkmark$ & & $\checkmark$ & $\checkmark$ & & & \\
\hline [23] & $\checkmark$ & $\checkmark$ & $\checkmark$ & & 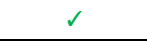 & & $\checkmark$ \\
\hline $\begin{array}{c}\text { Proposed } \\
\text { system } \\
\end{array}$ & $\checkmark$ & $\checkmark$ & $\checkmark$ & $\checkmark$ & $\checkmark$ & $\checkmark$ & \\
\hline
\end{tabular}




\section{Conclusion}

This paper proposes the use of the cooperative control method for power sharing, frequency, and voltage control in smart microgrids (SMGs) during grid-connected, islanding, and synchronizing modes. In the proposed control system, distributed cooperative control is utilized as the secondary and tertiary controllers for updating the dynamic set points of the local primary controllers. The effectiveness of the proposed control system is evaluated by the simulation results, and its pros and cons are discussed. The results show that the proposed method is able to share power such that each DG generates power proportional to its generation capacity at any given time. Therefore, the balance between input and output powers of VSIs are held. The proposed method stabilizes the frequency and voltage of the SMG by returning the upset output frequencies and voltages of VSIs to the desired values. It is also able to match the frequency and voltage of the SMG in agreement with the main grid for reconnection as demonstrated by the results.

The distributed cooperative control systems are large-scalable and self-organizing with minimum communication links. In the SMGs controlled by cooperative control systems, DGs can be connected in a plug-and-play manner that increases the system operability.

\section{Appendix A}

First, a review on inverter models is presented, then the used model in this work is described in detail. In [31] and [32], a first-order transfer function is utilized to model Primary Energy Source (PES) dynamics and the VSI dynamics is neglected. In [33], PES dynamics are considered in detail; however, similar to [31], [32], VSI dynamics is neglected. In [34], the complete model of both PES and VSI are used. Although this is the most complete model, fast dynamics of VSIs are 


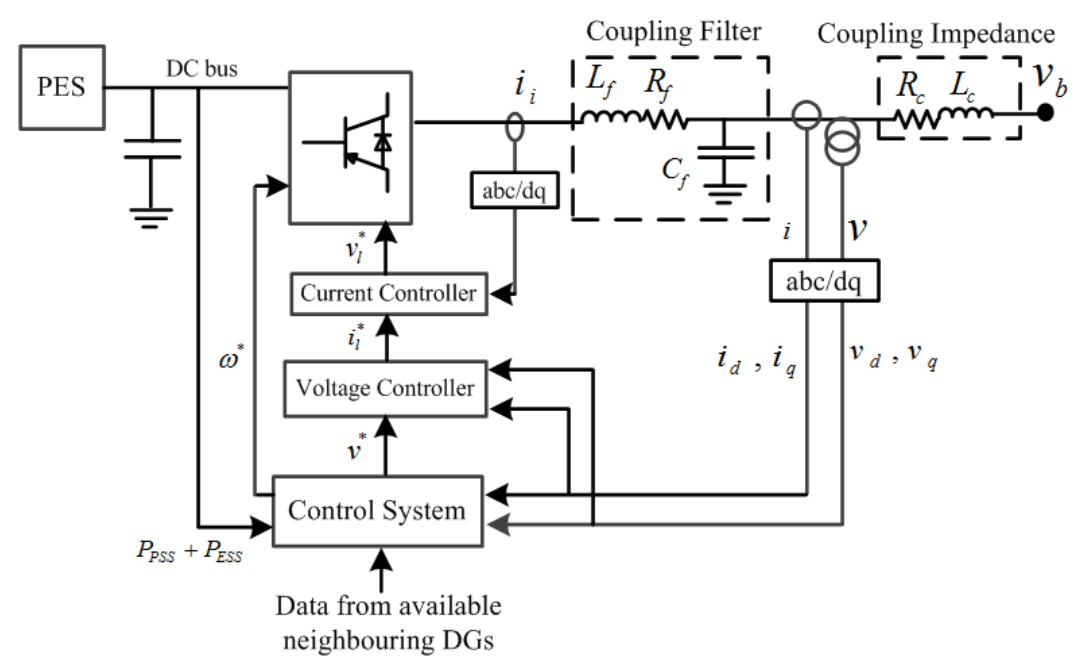

Fig. A. 1. Block diagram of VSI-based DGs.

negligible compared to the slow changing power flow variables. Therefore, it is an acceptable approximation to neglect the inverter dynamics, as we assumed in this work. The block diagram of the model utilized in this paper is shown in Fig. A. 1. The list of the components is as follows:

1) PES: in this work, first-order transfer functions are used for modeling the PESs. The transfer function time constants are equal to the largest time constant of the PESs [9], [32], and PES time constants are given in Appendix B.

2) DC Bus: Each DC bus has a capacitor. In this work, DC bus voltages are calculated as follows [8], [9]

$$
P_{P E S}(t)+P_{E S S}(t)=\sum_{i=1}^{3} P_{\Phi_{i}}(t)+\sum_{i=1}^{3} Q_{\Phi_{i}}
$$

where $P_{P E S}$ are $P_{E E S}$ are the outputs of PES and ESS, respectively, $P_{\Phi_{i}}$ and $Q_{\Phi_{i}}$ are the active and reactive outputs of phase $i$. According to [6], in three-phase VSIs, $\sum_{i=1}^{3} Q_{\Phi i}=0$, hence DC bus voltage variation is

$$
\frac{1}{2} C V_{D C}^{2}(t)-\frac{1}{2} C V_{D C}^{2}(t-\Delta t)=\left(P_{P S S}+P_{E E S}-P_{V S I}\right) \Delta t
$$


Where $C$ is DC bus capacitance, $V_{D C}$ is DC bus voltage, $P_{V S I}$ is VSI output power, and $\Delta t$ is simulation time step.

3) Voltage Controller: The voltage controller Differential Algebraic Equations (DAEs) are [5], [9]

$$
\left\{\begin{array}{c}
\dot{\phi}_{q_{i}}=V_{q_{i}}^{*}-V_{q_{i}} \\
\dot{\phi}_{d_{i}}=V_{d_{i}}^{*}-V_{d_{i}} \\
i_{l d_{i}}^{*}=F_{i} i_{d_{i}}-\omega C_{f_{i}} V_{q_{i}}+k_{P V_{i}}\left(V_{d_{i}}^{*}-V_{d_{i}}\right)+k_{I V_{i}} \phi_{d_{i}} \\
i_{l q_{i}}^{*}=F_{i} i_{q_{i}}-\omega C_{f_{i}} V_{d_{i}}+k_{P V_{i}}\left(V_{q_{i}}^{*}-V_{q_{i}}\right)+k_{I V_{i}} \phi_{q_{i}}
\end{array}\right.
$$

where $\phi_{q_{i}}$ and $\phi_{d_{i}}$ are the state variables corresponding to the $i^{\text {th }}$ voltage PI controller, $K$ 's are the integrator gain factors, and the other parameters are shown in Fig. A. 1.

4) Current Controller: The current controller DAEs are [5], [9]

$$
\left\{\begin{array}{c}
\dot{\gamma}_{d_{i}}=i_{l d_{i}}^{*}-i_{l d_{i}} \\
\dot{\gamma}_{q_{i}}=i_{l q_{i}}^{*}-i_{l q_{i}} \\
V_{d_{i}}^{*}=-\omega L_{f} i_{l q_{i}}+k_{P C_{i}}\left(i_{l d_{i}}^{*}-i_{l d_{i}}\right)+k_{I C_{i}} \gamma_{d_{i}} \\
V_{q_{i}}^{*}=-\omega L_{f} i_{l d_{i}}+k_{P C_{i}}\left(i_{l q_{i}}^{*}-i_{l q_{i}}\right)+k_{I C_{i}} \gamma_{q_{i}}
\end{array}\right.
$$

where $\gamma_{d_{i}}$ and $\gamma_{q_{i}}$ are the state variables corresponding to the $i^{\text {th }}$ current PI controller, $K$ 's are the integrator gain factors, and the other parameters are shown in Fig. A. 1.

5) Coupling Circuit: It includes the output filter and the coupling inductance, as shown in Fig. A.

1. The coupling circuit DAEs are [5], [9]

$$
\left\{\begin{array}{c}
\dot{i}_{l d_{i}}=-\frac{r_{f_{i}}}{L_{f_{i}}} i_{l d_{i}}+\omega_{i}^{*} i_{l q_{i}}+\frac{1}{L_{f_{i}}} V_{i d_{i}}-\frac{1}{L_{f_{i}}} V_{d_{i}} \\
\dot{i}_{l q_{i}}=-\frac{r_{f_{i}}}{L_{f_{i}}} i_{l q_{i}}-\omega_{i}^{*} i_{l d_{i}}+\frac{1}{L_{f_{i}}} V_{i q_{i}}-\frac{1}{L_{f_{i}}} V_{q_{i}} \\
\dot{V}_{d_{i}}=\omega_{i}^{*} V_{q_{i}}+\frac{1}{C_{f_{i}}} i_{l d_{i}}-\frac{1}{C_{f}} i_{d_{i}} \\
\dot{V}_{q_{i}}=-\omega_{i}^{*} V_{d_{i}}+\frac{1}{C_{f_{i}}} i_{l q_{i}}-\frac{1}{C_{f_{i}}} i_{q_{i}} \\
\dot{i}_{d_{i}}=-\frac{r_{c_{i}}}{L_{c_{i}}} i_{d_{i}}+\omega_{i}^{*} i_{q_{i}}+\frac{1}{L_{c i}} V_{d_{i}}-\frac{1}{L_{c_{i}}} V_{b d} \\
\dot{i}_{q_{i}}=-\frac{r_{c_{i}}}{L_{c_{i}}} i_{q_{i}}-\omega_{i}^{*} i_{d_{i}}+\frac{1}{L_{c_{i}}} V_{q_{i}}-\frac{1}{L_{c_{i}}} V_{b q}
\end{array}\right.
$$


where $i_{l d_{i}}$ and $i_{l q_{i}}$ are the direct and quadratic components of the $i^{\text {th }}$ filter current, and the other parameters are shown in Fig. A. 1.

\section{Appendix B}

The details of VSIs used in the case study according to the formulations in Appendix A are selected from [5], [6], [8], [9] with occasional amendments with respect to their capacities:

$\mathrm{VSI}_{1}$ to $\mathrm{VSI}_{3}, F=0.75, k_{P V}=0.1, k_{I V}=400, k_{P C}=15, k_{I C}=16000, L_{f}=0.1[\mathrm{mH}], C_{f}=67.5[\mu \mathrm{F}]$, $r_{f}=0.01[\Omega], L_{C}=0.03[\mathrm{mH}], K_{P}=K_{Q}=0.42, K_{\omega}=0.6, K_{V}=2.25$, PES time constant $=0.7[\mathrm{~s}]$.

$\mathrm{VSI}_{4}$ and $\mathrm{VSI}_{5}, F=0.75, k_{P V}=0.1, k_{I V}=400, k_{P C}=15, k_{I C}=16000, L_{f}=0.135[\mathrm{mH}], C_{f}=50[\mu \mathrm{F}]$ , $r_{f}=0.015[\Omega], L_{C}=0.035[\mathrm{mH}], K_{P}=K_{Q}=0.42, K_{\omega}=0.7, K_{V}=1.68$, PES time constant $=0.5[\mathrm{~s}]$.

Relatively large PES time constants are selected to make the situation worse in the case study.

\section{Appendix C}

Laplacian matrices relating to the case study are

$$
\boldsymbol{L}_{P}=\boldsymbol{L}_{Q}=\left[\begin{array}{ccccc}
1 & -1 & 0 & 0 & 0 \\
-1 & 2 & -1 & 0 & 0 \\
0 & -1 & 2 & -1 & 0 \\
0 & 0 & -1 & 2 & -1 \\
0 & 0 & 0 & -1 & 1
\end{array}\right], \boldsymbol{L}_{\omega}=\boldsymbol{L}_{V}=\left[\begin{array}{ccccc}
1 & -1 & 0 & 0 & 0 \\
0 & 1 & -1 & 0 & 0 \\
0 & 0 & 1 & -1 & 0 \\
0 & 0 & 0 & 0 & 0 \\
0 & 0 & 0 & -1 & 1
\end{array}\right]
$$

Eigen-values of $\left(-\boldsymbol{L}_{P}\right)=\left(-\boldsymbol{L}_{Q}\right)=\{0,-0.38,-2.62,-3.62,-1.38\}$, and eigen-values of $\left(\boldsymbol{L}_{\omega}=\boldsymbol{L}_{V}\right)=\{0,-1,-1,-1,-1\}$. Since all the eigen-values are negative except for exactly one zero-eigenvalue, both systems are BIBO stable and converge to $\alpha[1,1, \ldots 1]^{T}$ where $\alpha$ is a real number [25]. Cooperative controller input matrices are:

$$
\boldsymbol{B}_{P}=\boldsymbol{B}_{Q}=\boldsymbol{B}_{\omega}=\boldsymbol{B}_{V}=[0,0,0,1,0]^{T}
$$

Only $\mathrm{DG}_{4}$ directly receives the control signals from the critical point, as shown in Fig. 4. 


\section{References}

[1] Microgrid Institute, Microgrid Definition, Available On-line: http://www.microgridinstitute.org.

[2] J. M. Guerrero, P. C. Loh, T. Lee, M. Chandorkar, Advanced control architectures for intelligent microgridsPart II: power quality, energy storage, and AC/DC microgrids, Industrial Electronics, IEEE Trans. on, Vol. 60, No. 4, 2013, pp. 1263-1270.

[3] J. A. Pecas Lopes, C. L. Moreira, A. G. Madureira, Definig control strategies for microgrids islanded operation, Power Systems, IEEE Trans. on, Vol. 21, No. 2, 2006, pp. 916-924.

[4] A. Mohda, E. Ortjohanna, D. Mortonb, O. Omaric, Review of control techniques for inverters parallel operation, Electric Power Systems Research, Vol. 80, No. 12, Dec. 2010, pp. 1477-1487.

[5] A. Bidram, A. Davoudi, F. L. Lewis, J. M. Guerrero, Distributed cooperative secondary control of microgrids using feedback linearization, Power Systems, IEEE Trans. on, Vol. 28, No. 3, Aug. 2013, pp. 3462-3470.

[6] A. Bidram, A. Davoudi, F. L. Lewis, S. S. Ge, Distributed adaptive voltage control of inverter-based microgrids, Energy Conversion, IEEE Trans. on, Vol. 29, No. 4, 2014, pp. 862-872.

[7] F. Katiraei, M. Iravani, Power management strategies for a microgrid with multiple distributed generation units, Power Systems, IEEE Trans. on, Vol. 21, No. 4, Nov. 2006, pp. 1821-1831.

[8] A. Bidram, A. Davoudi, F. L. Lewis, Z. Qu, Secondary control of microgrids based on distributed cooperative control of multi-agent systems; Generation, Transmission \& Distribution; IET, Vol. 7, No. 8, pp. 822-831, 2013.

[9] P. H. Divshali, A. Alimardani, S. H. Hosseinian, M. Abedi, Decentralized cooperative control strategy of microsources for stabilizing autonomous VSI-based microgrids, Power Systems, IEEE Trans. on, Vol. 27, No. 4, Nov. 2012, pp. 1949-1959.

[10] H. Xin, Z. Qu, J. Seuss, A. Maknouninejad, A self-organizing strategy for power flow control of photovoltaic generators in a distribution network, Power Systems, IEEE Trans. on, Vol. 26, No. 3, 2011, pp. 1462-1473.

[11] A. Maknouninejad, W. Lin, H. G. Harno, Z. Qu, M. A. Simaan, cooperative control for self-organizing microgrids and game strategies for optimal dispatch of distributed renewable generations, Springer's Journal of Energy Systems, Vol. 3, No.1, 2012, pp.23-60.

[12] A. Maknouninejad, Z. Qu, Realizing unified microgrid voltage profile and loss minimization: a cooperative distributed optimization and control approach, Smart Grid, IEEE Trans. on, Vol. 5, No. 4, 2014, pp. 1621-1630.

[13] M. Peydayesh, R. Baldick, The effect of very fast response to frequency fluctuations, The University of Texas at Austin, Electrical Engineering Department, Available on-line: http://www.usaee.org/usaee2012/submissions/Presentations/peydayesh.pdf.

[14] T. M. L. Assis, G. N. Taranto, Automatic reconnection from intentional islanding based on remote sensing of voltage and frequency signals, Smart Grid, IEEE Trans. on, Vol. 3, No. 4, Dec. 2012, pp. 1877-1884.

[15] A. Mehrizi-Sani, R. Iravani, Potential-function based control of a microgrid in islanded and grid-connected models, Power Systems, IEEE Trans. on, Vol. 25, No. 4, Nov. 2010, pp. 1883-1891.

[16]Q. Shafiee, J. M. Guerrero, J. C. Vasquez, Distributed secondary control for islanded microgrids-a novel approach, Power Electronics, IEEE Trans. on, Vol. 29, No. 2, Feb. 2014, pp. 1018-1031. 
[17] The Smart Grid, Available On-line: https://www.smartgrid.gov/the_smart_grid/smart_grid.

[18] J. M. Guerrero, J. C. Vsquez, J. Matas, M. Castilla, L. G. d. Vicua, M. Castilla, Hierarchical control of droopcontrolled AC and DC microgrids a general approach toward standardization, Industrial Electronics, IEEE Trans. on, Vol. 58, No. 1, Jan. 2011, pp. 158-172.

[19] A. Vaccaror, G. Velotto, A. F. Zobaa, A decentralized and cooperative architecture for optimal voltage regulation in smart grids, Industrial Electronics, IEEE Trans. on, Vol. 58, No. 10, Oct. 2011, pp. 4593-4602.

[20] A. Maknouninejad, Z. Qu, J. Enslin, A. Hussam, N. Kutkut, Clustering and cooperative control of distributed generators for maintaining microgrid unified voltage profile and complex power control, IEEE Transmission and Distribution Conference and Exposition (T\&D), 2012 IEEE PES, 2012, pp. 1-8.

[21] H. Farag, E. F. El-Saadany, A novel cooperative protocol for distributed voltage control in active distribution systems, Power Systems, IEEE Trans. on, Vol. 28, No. 2, May 2013, pp. 1645-1656.

[22] A. Maknouninejad, W. Lin, Z. Qu, Optimum design and analysis of the cooperative control, applied to the distributed generators control in smart grids, IEEE Innovative Smart Grid Technologies (ISGT), Feb 24-27, 2013, pp. $1-6$.

[23] J. Kim, J. Jeon, S. Kim, C. Cho, H. Kim, K. Young Nam, Cooperative control strategy of energy storage system and microsources for stabilizing the microgrid during islanded operation, Power Electronics, IEEE Trans. on, Vol. 25, No. 12, Dec. 2010, pp. 3037-3048.

[24] A. Vaccaro, V. Loia, G. Formato, P. Wall, V. Terzija, A self organizing architecture for decentralized smart microgrids synchronization, control and monitoring, Industrial Informatics, IEEE Trans. on, Vol. 11, No. 1, Jul. 2014, pp. 289-298.

[25]Z. Qu, Cooperative control of dynamic systems, Springer Science \& Business Media, 2009.

[26] R. Olfati-Saber, J. A. Fax, R. M. Murray, Consensus and cooperation in networked multi-agent systems, Proceedings of the IEEE, Vol. 95, No. 1, 2007, pp. 215-233.

[27] A. Bidram, F. L. Lewis, A. Davoudi, Distributed control systems for small-scale power networks: using multiagent cooperative control theory, Control Systems, IEEE, Vol. 34, No. 6, 2014, pp. 56-77.

[28] D. E. Olivares, A. Mehrizi-Sani, A. H. Etemadi, C. A. Cañizares, R. Iravani, M. Kazerani, A. H. Hajimiragha,O. Gomis-Bellmunt, M. Saeedifard, R. Palma-Behnke, G. A. Jiménez-Estévez, N. D. Hatziargyriou, Trends in microgrid control, Smart Grid, IEEE Trans. on, Vol. 5, No. 4, Jul. 2014, pp. 1905-1919.

[29]D. P. Kothari, I. J. Nagrath, Modern power system analysis, Tata McGraw-Hill Education, Third Edition, 2003.

[30] IEEE Std., IEEE recommended practice for industrial and commercial power systems analysis (Brown Book), IEEE Std. 399-1997, 1998, pp. 1-488.

[31] T. Senjyu, T. Nakaji, K. Uezato, T. Funabashi, A hybrid power system using alternative energy facilities in isolated island, Energy Conversion, IEEE Trans. on, Vol. 20, No. 2, Jun. 2005, pp. 406-414.

[32]D. J. Lee, L. Wang, Small-signal stability analysis of an autonomous hybrid renewable energy power generation/energy storage system, Part I: Time-domain simulations, Energy Conversion, IEEE Trans. on, Vol. 23, No. 1, Mar. 2008. 
[33] Y. Zhu, K. Tomsovic, Development of models for analyzing the load following performance of microturbines and fuel cells, Electric Power Systems Research, Vol. 62, No. 1, May. 2002, pp. 1-11.

[34] M. Shen, A. Joseph, J. Wang, F. Z. Peng, D. J. Adams, Comparison of traditional inverters and Z-source inverter for fuel cell vehicles, Power Electronics, IEEE Trans. on, Vol. 22, No. 4, Jul. 2007, pp. 125-132. 